American Journal of Applied Sciences 6 (5): 816-819, 2009

ISSN 1546-9239

(C) 2009 Science Publications

\title{
Evaluation of Tensile Strength of the Superficial Digital Flexor Tendon in Horses Subjected to Transcutaneous Electrical Neural Stimulation Therapeutic Regimen
}

\author{
${ }^{1}$ Davood Sharifi, ${ }^{2}$ Davood Kazemi and ${ }^{3}$ Hadi Latifi \\ ${ }^{1}$ Department of Clinical Sciences, Surgery and Radiology Section, \\ Faculty of Veterinary Medicine, University of Tehran, Tehran, Iran \\ ${ }^{2}$ Department of Clinical Sciences, Surgery and Radiology Section, \\ Faculty of Veterinary Medicine, Islamic Azad University, Tabriz Branch, Iran \\ ${ }^{3}$ Department of Biomedical Engineering, Amirkabir University of Technology, Tehran, Iran
}

\begin{abstract}
We would like to sincerely express our gratitude to the university of Tehran and faculty of veterinary medicine research council for approval and financial support for this extensive evaluation of tensile strength of the superficial digital flexor tendon in horses subjected to Transcutaneous Electrical Neural Stimulation (TENS) therapeutic regimen Problems statement: The purpose of this study was to determine the effect of TENS on the tensile strength of experimentally traumatized SDFT in horses. Approach: Eight adult castrated horses between 4-9 years-old and 310-395 Kg body-weight were considered. The left fore-limb superficial digital flexor tendon of each horse was splitted longitudinally in the middle portion in full thickness of $10 \mathrm{~cm}$ in length using B.P. blade (15 Times strike), then the connective tissue and skin were approximated using No 2 Nylon. Horses were divided into two groups of control and treated with 4 horses each. No treatment was given to control one, whereas treated group was subjected to the transcutaneous electrical neural stimulation (Newtens 900c) therapeutic regimens 10 min daily with intensity of $80 \mu \mathrm{s}, 100 \mathrm{~Hz}$ frequency for 14 days. After 60 days, the full length of SDFT $(20 \mathrm{~cm})$ was removed from the right normal countralaleral and left traumatized tendon of control and treated limbs of all horses to be subjected to test of tensile strength using Zwick/Roell MDTL Machine with speed of $0.07 \mathrm{mM} \mathrm{sec}^{-1}$ having Proportional Integral Deferential (PID) controller. In assessing the variation obtained data was analyzed using paired-t-test. Results: Data of the tensile strength was revealed an average $0.6625 \mathrm{KN}$ for normal SDFT, $0.6375 \mathrm{KN}$ for treated tendon and $0.6175 \mathrm{KN}$ for control tendon .There was significant improvement in regaining tensile strength in treated tendons comparison to control ones in Conclusion: TENS significantly accelerated healing and remodeling of traumatized tendon to regain its tensile strength.
\end{abstract}

Key words: Tensile strength, SDFT, horse, splitting, TENS

\section{INTRODUCTION}

The superficial digital flexor tendon is one the strongest tendon in the horse body and possesses great tensile strength and low extensibility which serves primarily as a force transmitter and acts as a dynamic amplifier during rapid muscle contraction ${ }^{[5]}$. The greatest risk of tendon rupture is when the tendon is obliquely loaded, the muscle is contracting maximally and tendon length is short ${ }^{[6,16]}$. This usually occurs as results of pushing off with the foot against resistance and is very common in males in the fourth decade. As hence, the rupture of this tendon is very frequent and begins to disrupt after 3\% increase in length and will rupture when it is about $8 \%^{[3,4]}$. The ideal tendinous repair must besides morphological reconstitute the injured tissue and preserve the sliding function of the tendon ${ }^{[9]}$, helping to maintain the movement capacity and regain the tensile strength ${ }^{[3,7,8]}$ Despite of frequent application of TENS to subside the clinical inflammatory signs in human athletes and even companion animals referred cases, there is controversy about the actual positive effect of TENS in healing of tendinous tissue and increasing its tensile strength in human and animal cases ${ }^{[5,14]}$, that is why we investigated the ultimate strength to failure point and

Corresponding Author: Davood Sharifi, Department of Clinical Sciences, Surgery and Radiology Section, Faculty of Veterinary Medicine, University of Tehran, P.O. Box 14155-6453, Tehran, Iran Fax: 0098-21-66933222 
the pattern and effect of TENS on repair of severely traumatized tendon and its gained tensile strength too between two groups.

\section{MATERIALS AND METHODS}

Using 8 adult castrated horses having 310-395 Kg body weight with 4-9 years of age. The mid part of left fore-limb superficial digital flexor tendon was splitted longitudinally in full thickness of $10 \mathrm{~cm}$ in length using B.P. blade (15 Times strike) under deep surgical anesthesia the connective tissue and skin were approximated using No 2 Nylon. Horses were divided into two groups of control and treated with 4 horses each. No treatment was given to control one (untreated tendon), whereas treated group was subjected to the transcutaneous electrical neural stimulation (New tens 900c) therapeutic regimens for $10 \mathrm{~min}$ daily with intensity of $80 \mu \mathrm{s}, 100 \mathrm{~Hz}$ frequency during 14 days.

On the 60 day after traumatizing tendons, the full length of SDFT $(20 \mathrm{~cm})$ was removed from the right countralateral normal tendon, the left control tendon and left treated one in all horses to be subjected to test of tensile strength using Zwick/Roell MDTL Machine with speed of $0.07 \mathrm{~mm} \mathrm{sec}^{-1}$ and Proportional Integral Deferential( PID) controller , the both cut ends of each tendon were grasped and tightly secured with dentition compansment (Fig. 1 and 2). In assessing the variation of tensile strength collected data were analyzed using paired-t-test ( $p>0.02$.).

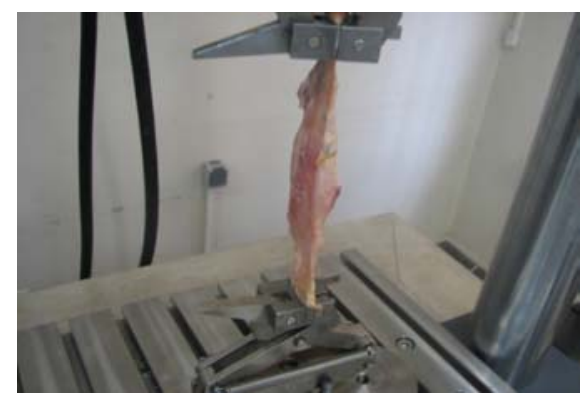

Fig. 1: Fixation of both ends of tendon with clips of Tensile machine

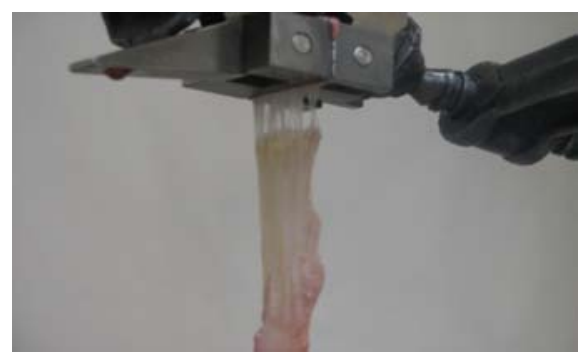

Fig.2: Disruption of tendon
Post operative care: Extensive care of daily wound dressing till removal of sutures on 12th day was employed. Intramascular injection of Vetacoid (dexamethasone $0.05 \mathrm{mg} \mathrm{kgbw}^{-1}$, Aburaihan Co. Iran) Intravenous injection of Vetanyl \%2 (Phenylbutazone $4.4 \mathrm{mg} \mathrm{kgbw}{ }^{-1}$ Aburaihan Co. Iran) Intramuscular injection of Vitamine AD3E $10 \mathrm{~mL}$ total body weight.Interchemie.Holland) and intramuscular injection of Penicillin G, Benzathine, Procaine and Potassium 2:1:1,500oIU $\mathrm{kgbw}^{-1}$. Nasr Fariman Co. Iran for 5 days was used.

\section{RESULTS}

The mean ultimate tensile strength was $0.6625 \mathrm{KN}$, $0.6375 \mathrm{KN}$ and $0.6175 \mathrm{KN}$ for normal, treated and control tendon, respectively (Fig. 3-5). This study revealed that, there is significant difference in ultimate strength between normal, treated and control tendon (Fig. 6 and 7).

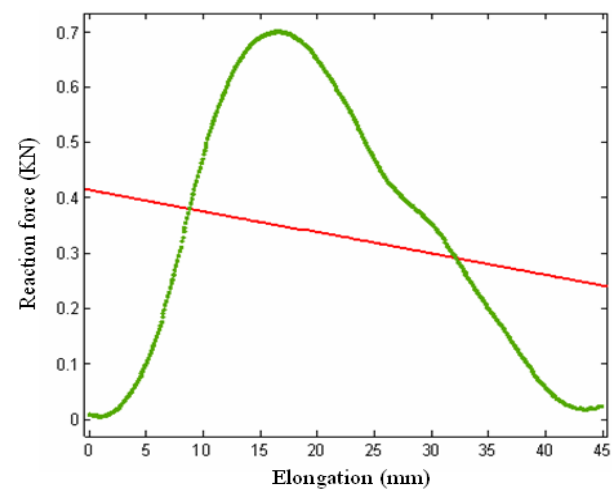

Fig. 3: Normal tendon $(\mathrm{Lo}=20 \mathrm{~cm})$. (Note that green line is the curve that given with machine and red line is the average force given by Mat Lab software)

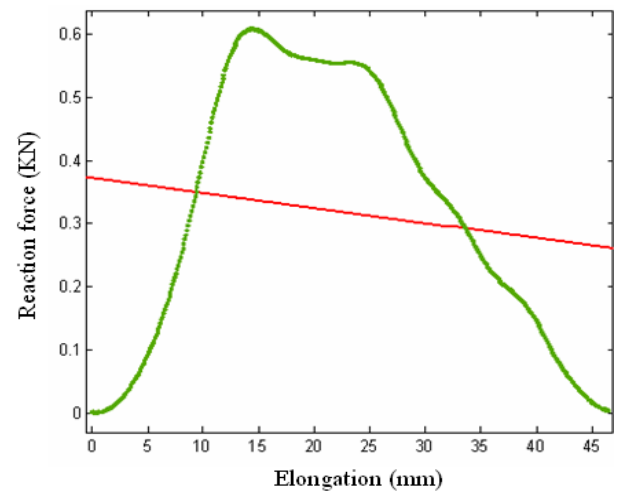

Fig. 4: Control tendon $(\mathrm{Lo}=20 \mathrm{~cm})$. (Note that green line is the curve that given with machine and red line is the average force given by Mat Lab software) 


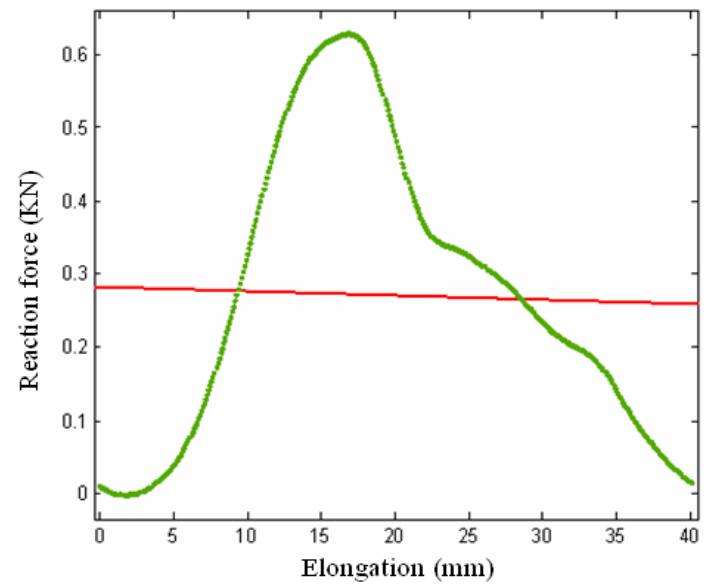

Fig. 5: Treated tendon $(\mathrm{Lo}=20 \mathrm{~cm})$. (Note that green line is the curve that given with machine and red line is the average force given by Mat Lab software)

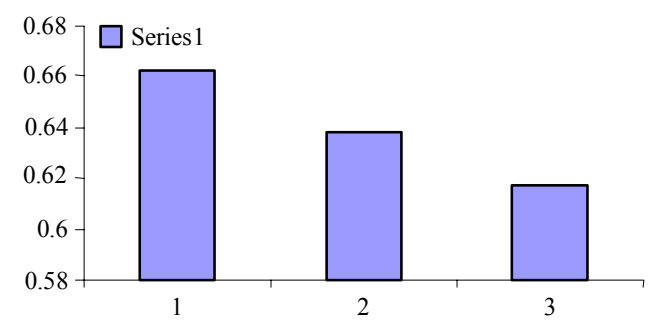

Fig. 6: Comparative (Means $\pm \mathrm{SE}(\mathrm{SE}=0.001 \mathrm{KN})$ ) of tensile strength in normal (1), treated (2) and control tendon (3) (force via $\mathrm{KN}$ )

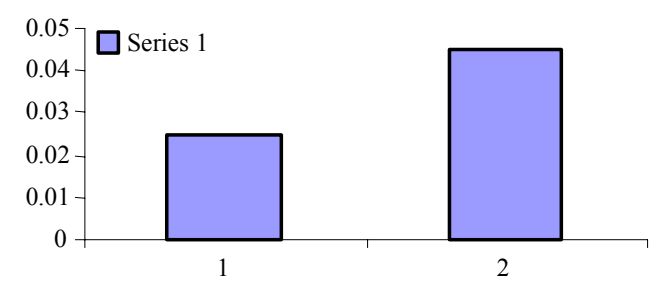

Fig. 7: Comparative differences (Means $\pm \mathrm{SE}$ $(\mathrm{SE}=0.001 \mathrm{KN}))$ of tensile strength in control (1) and treated (2) with that of normal tendons (force via $\mathrm{KN}$ )

\section{DISCUSSION}

The goals of rehabilitation following tendon reconstruction are to restore strength (muscle forcegenerating capacity) without subjecting the horse to excessive forces that may hinder healing or rupture the repair ${ }^{[18]}$.Tendons and ligaments must withstand high tensile stress forces and therefore contain a high proportion of type I collagen molecules ${ }^{[4,6,15]}$ which is responsible for the excellent tensile properties of tendons tissues. Large fibers predominate in normal tendon, but 3 distinct sizes (small, medium and large) have been identified ${ }^{[17]}$. Small fibers are weaker than large fibers, so tendons with increased proportions of small fibers, as found in the early stages of repair, are structurally inferior as healing progresses, fibril diameter increases and, along with increasing crosslinks, are responsible for the acquisition of strength by healing tendon. The mechanical behavior of equine tendon has been investigated and data have been reported for strain, modulus of elasticity and estimates of in vivo loading ${ }^{[3,10-12]}$. The superficial digital flexor tendon which tensile strength is about $600-750 \mathrm{~N}^{-1} \mathrm{mM}$ (1.2) Loads of more than $12000 \mathrm{~N}$ rupture the equine superficial digital flexor tendon. Tensile strain at failure for this tendon varies from as low as $10-20 \%(3)$. The crimp pattern in the central core of the superficial digital flexor tendon of older horses differs from the pattern in the peripheral fibers ${ }^{[5,8]}$ with loading, these fibers when subjected to increased strain, may be increase rupture of fiber so recent findings could explain the characteristic of the core lesion in tendonitis.

Injury to tendon results in damage to its cells and matrix, which incites an inflammatory response. The early fibro vascular tissue filling the tendon defect is a poorly organized mass of immature collagen that possesses little tensile $\operatorname{strength}^{[19,20]}$.In the remodeling phase of repair the immature collagenous structure is replaced with type I collagen fibrils contained within fiber bundles which were oriented longitudinally along the lines of tension. Tensile strength of the healing tendon increases by factor of 3 from week 8 to week $12^{[13]}$. By 24 weeks after injury, repair tissue developed into a mature scar with longitudinally oriented tendon fiber bundles composed of primarily type I collagen fibrils. However, some immature collagenous tissue is retained, which is inferior to normal tissue and may be predisposing the area of the tendon scar to reinjury. According to our findings TENS showed to have positive effect on the reorganization of collagen fibers in treated tendons, in addition accelerating tensile strength compared to that of control tendons.

\section{CONCLUSION}

TENS beside being useful to reduce clinical signs of inflammation is quite effective in reorganization of the collagen bundles. 


\section{REFERENCES}

1. Bosch, P., H. Hertz, F. Lintner, R. Nowotny and Engel, 1982. A1-Experimenttelle Sehnenklebung. In: Fibrinkleber in Orthopedic und Traumatologie, Cotta, Braun, H.A. (Eds.). Stuttgart, ThemeVerlag, pp: 187.

2. Carina Forslund, 2003. BMP treatment for improvement tendon repair. Acta Orthopaed. Scandinav., $\quad 74: \quad 1-33$. DOI: 10.1080/03008820310014118.

3. Crevier, N., P. Pourcelot and J.M. Denoix, 1996. Segmental variation of in vitro mechanical properties in equine superficial digital flexor tendons. Am. J. Vet. Res., 57: 1111-1117. http://www.ncbi.nlm.nih.gov/pubmed/8836359.

4. Davison, P.F., 1996. Collagen in Health and Disease Tendon Jayson MIV. 1st Edn., Edinburgh Churchill Livingston, Edinburgh, pp: 498-505.

5. Goodship, A.E., H.L. Birch and A.M. Wilson, 1994. The pathobiology and repair of tendon and ligament injury. Vet. Clin. North Am. Equine Pract., 10: 323-349. http://www.ncbi.nlm.nih.gov/pubmed/7987721.

6. Evas, J.H. and J.C. Barbenel, 1975. Structural and mechanical properties of tendon related to function. Equine Vet. J., 7: 1-8. http://www.ncbi.nlm.nih.gov/pubmed/1116491.

7. Eiken, O., G. Lundborg and F. Rank, 1975. The role of the digital synovial sheath in tendongrafting. Scand. J. Plast. Reconstr. Surg., 9: 182-189. DOI: $10.3109 / 02844317509022864$.

8. Feehan, L.M. and J.G. Beauchene, 1990. Early tensile properties of healing chicken flexor tendons: Early controlled passive motion versus postoperative immobilization. J. Hand Surg. (Am.), 15: 63-68. http://cat.inist.fr/?aModele=afficheN\&cpsidt=6893060.

9. Frykman, L.M., S. Jacobsson and B. Widenfalk, 1993. Fibrin sealant in prevention of flexor tendon adhesions: An experimental study in the rabbit. J. Hand Surg. (Am.), 18: 68-75. http://www.ncbi.nlm.nih.gov/pubmed/8423322?do $\mathrm{pt}=$ Abstract.

10. Gelberman, R.H. and P.R. Manske, 1985. Factors influencing flexor tendon adhesions. Hand Clin., 1 : $35-42$. http://www.ncbi.nlm.nih.gov/pubmed/4093463?do $\mathrm{pt}=$ Abstract.
11. Lochner, F.K., D.W. Milne and I.J. Groom, 1980. In vivo and in vitro measurement of tendon strain in the horse. Am. J. Vet. Res., 41: 1929-1937. http://www.ncbi.nlm.nih.gov/pubmed/7212427.

12. Mcclelland, D. and N. Maffulli, 2002. Percutaneous repair of ruptured achilles tendon. J. R. Coll. Edinb., 47: 613-618. http://owl.orthogate.org/Detailed/14239.html.

13. Nixon, A.J., T.S. Stashak, F.W. Smith and R.W. Norrdin, 1984. Comparison of carbon fibre and nylon suture for repair of transected flexor tendons in the horse. Equine Vet. J., 16: 93-102. http://www.fao.org/agris/search/display.do?f=./199 0/v1611/GB8803751.xml;GB8803751.

14. Levine, P.M., T.F. George and S.M. Green, 2004. Biomechanical strength of rabbit FDP tendons repaired and supplemented with Octyl-2cyanoacrylate. American Academy of Orthopedic Surgeons. San Francisco.

15. Burks, R., W. Burke and M. Stevanovic, 2006. Rehabilitation following repair of a torn latissimus dorsi tendon. Phys. Ther., 86: 411-423. http://www.ncbi.nlm.nih.gov/pubmed/16506877?d opt $=$ Abstract.

16. Rosager, S., P. Aagaard, P. DYhre-Poulsen, K. Neergaard, M. Kjaer and S.P. Magnusson, 2002. Load-displacement properties of the human triceps surae aponeurosis and tendon in runners and nonrunners. Scand. J. Med. Sci. Sports, 12: 90-98. http://www.ncbi.nlm.nih.gov/pubmed/12121426.

17. Smith, K.W. and P.M. Webbon, 1996. The physiology of normal tendon and ligament. Proceedings of the Dubai International Equine Symposium, pp: 18-22.

18. Stewart, K.M., 1992. Tendon Injuries. In: Rehabilitation, Stanley, B.G. and S.M. Tribuzi (Eds.). Philadelphia, Pa., FA Davis Co., pp: 353-394.

19. Watkins, J.P., J.A. Auer, S. Gay and S.J. Morgan, 1985. Healing of surgical created defects in the equine superficial digital flexor tendons: Collagentype transformation and tissue morphologic reorganization. Am. J. Vet. Res., 46: 2091-2096. http://www.ncbi.nlm.nih.gov/pubmed/4062012.

20. Yamamoto, N. and K. Hayashi, 1998. Mechanical properties of rabbit patellar tendon at high strain rate. Biomed. Mater. Eng., 8: 83-90. http://www.ncbi.nlm.nih.gov/pubmed/9830991. 